
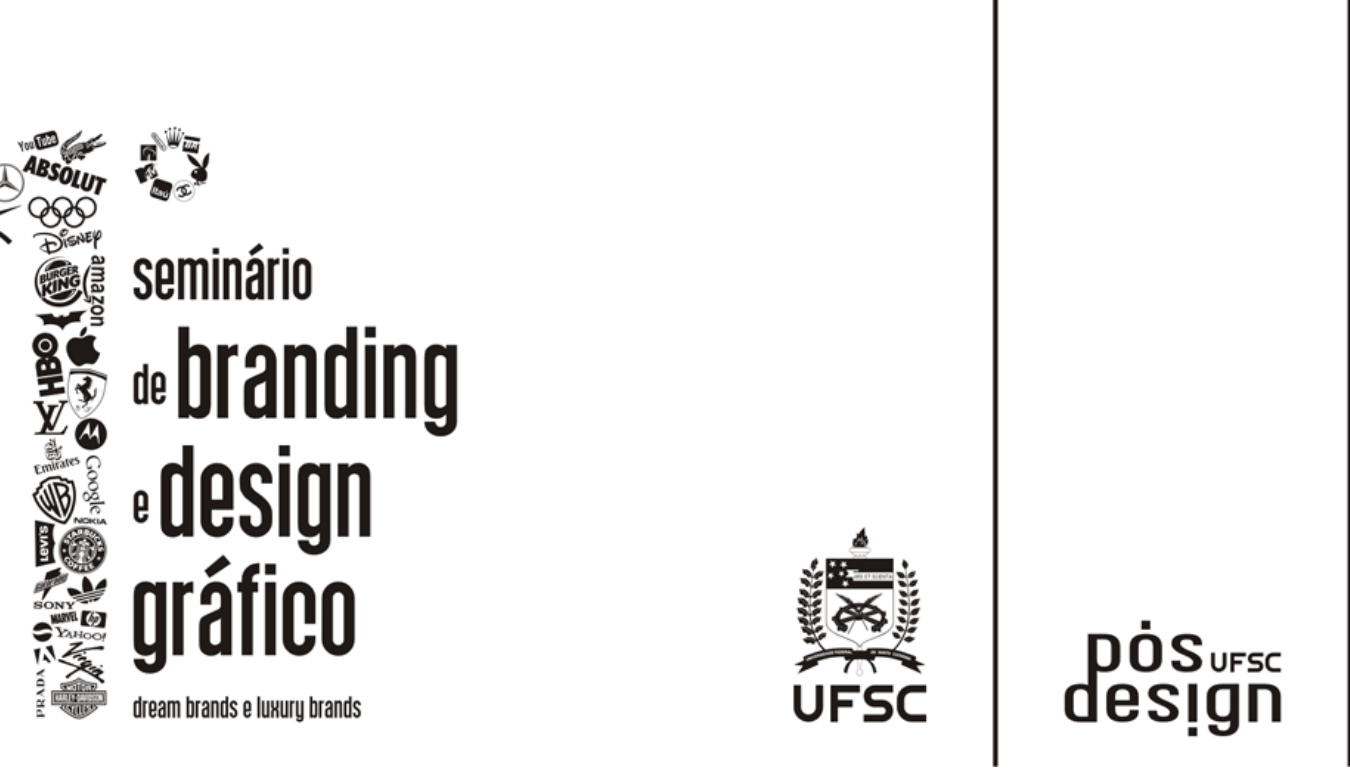

\title{
Projeto de marcas de abrangência e impacto global
}

\section{Design of brands with global coverage and impact}

Righeto, Flaviza; Tecnólogo em Design de Produto; Centro Federal de Educação Tecnológica flaviza@gmail.com

\section{Resumo}

A sociedade globalizada exige dos profissionais envolvidos no projeto de marcas e sua gestão, estudos específicos para que estas realmente efetuem sua comunicação em diferentes contextos sociais e econômicos. O presente artigo aborda a importância do profissional de design no branding e apresenta premissas iniciais para a criação de marcas de abrangência e impacto mundial.

Palavras Chave: marca; design gráfico; globalização.

\begin{abstract}
A globalized society requires to the professionals involved in the design of brands and their management, especifics studies so that they actually make your communication in different social and economic contexts. This article discusses the importance of professional design in branding and presents initial assumptions for the creation of brands of scope and impact worldwide.
\end{abstract}

Keywords: brand; graphic design; globalization. 


\title{
Introdução
}

A competição no mercado de consumo atual é notadamente crescente, as marcas despontam em grande volume e tomam cada vez mais espaço no competitivo mundo globalizado. Novos produtos chegam às prateleiras, novas empresas abarcam diferentes mercados e muitos outros desafios vêm à tona em termos de competição de mercado e gestão de marcas. Martins (2000, pg. 11-12) comenta esta realidade mundial:

\begin{abstract}
O excesso de ofertas - em todos os sentidos - em cada segmento de mercado irá levar a uma verdadeira "economia das marcas", pois elas serão importantes tanto para facilitar a vida dos consumidores como para alavancar os esforços dos vendedores. E será exatamente pelo grande aumento da força das marcas que o desafio de geri-las será constante, pois crescerá extraordinariamente tanto seu número como sua qualidade, tornando tão mais complexa sua construção e gestão, quanto maior for sua própria força. Isso significa que as marcas das grandes organizações mundiais serão ainda mais fortes. Essa situação forçará tanto as inúmeras companhias regionais e locais a dedicarem muito mais atenção, tempo e recursos para essa tarefa gerencial".
\end{abstract}

Neste contexto as marcas conquistam espaço como um diferencial competitivo chave, e o branding, responsável pela construção e gerenciamento das marcas, assume foco e atinge grande importância.

\begin{abstract}
A gestão de marcas constitui o grande desafio que se apresenta aos especialistas de marketing e de comunicação. (...) Ela tem a responsabilidade de desenvolver e manter determinado conjunto de valores e atributos construindo uma imagem de marca que se mostre coerente, apropriada e atrativa ao consumidor e que contribua para o estabelecimento da brand equity, como valor financeiro da empresa e como valor agregado à marca”. (PINHO, 1996, pg. 43-44).
\end{abstract}

O gerenciamento da marca é essencial para mantê-la na direção correta e atualizada com seu contexto histórico. Por ser um tema tão atual, o branding vem se destacando em sua missão de coordenar significação, criação e disseminação de marca e suas associações.

Na prática, branding significa fazer a marca ter valor, fazê-la acontecer. (...) O branding é a disciplina atual que se aproxima da descoberta ou da construção de valores e da representação deles através de uma marca junto aos variados públicos". (NASCIMENTO \& LAUTERBORN, 2007, p. 11-12).

O Branding é um processo bastante complexo que envolve diversos âmbitos de estudo e áreas de conhecimento como administração, marketing, publicidade, design gráfico entre outras. Essas áreas estão envolvidas por suas características gerenciais, organizacionais e de formação de significado. Villas-Boas (1998, pg. 26-27) fundamenta a posição do designer nesse universo: 
O design gráfico está diretamente ligado ao estabelecimento do valor de troca, ainda que pela via simbólica. Essa função subjetiva acompanha tanto os objetos de design gráfico que visam vender uma mercadoria quanto àqueles que buscam persuadir ou guiar a fruição do material pelo usuário, ainda que pareça mais claro no primeiro caso. (...) $\mathrm{O}$ design gráfico, entre tal, necessariamente tem com função transcrever a mensagem a ser transmitida - seja de qual enfoque for - para o código simbólico estabelecido, sobre pena de não efetivar-se enquanto prática comunicacional”.

O design gráfico se mostra como ferramenta de fundamental importância para a diferenciação de uma marca no mercado e no pensamento do consumidor, na criação de personalidade, emoção e sentimento na relação da marca com seu contexto. O profissional de design, por sua característica multidisciplinar, agrega conhecimentos de semiótica, sintaxe visual, teoria da forma e cor, entre outros conhecimentos antropológicos, psicológicos e sociais e se mostra como um dos profissionais mais importantes essencial no processo de criação e gestão da marca.

\section{Projetando marcas globais}

O designer, em meio ao mundo globalizado deve, na criação de uma marca e sua personalidade, estar atento aos aspectos de contexto social e econômico, não apenas da sua região mas como do mundo inteiro, por onde a marca percorrerá e disseminará sua expressão e emoção.

As relações multinacionais tornam o ambiente de estudo do designer, um pouco mais complexo e abrangente, e tornam seu trabalho mais minucioso, cauteloso e amplo. Segundo Roellig (2007, pg.2) a construção do universo da marca numa compreensão local, regional ou nacional já aborda demarcações de foco importantes como peculiaridade de público alvo e localidades. Em marcas de abrangência global estas áreas de definições se tornam ainda mais diversas e complexas. Roellig (2007,pg.2) Ele também cita alguns aspectos a serem considerados antes da fundação e solidificação dos ideais da empresa, como atributos centrais, personalidade, posicionamento pela categoria de mercado, público alvo, concorrentes, e mesmo as atitudes e ideais de seus próprios empregados. Além disso, existem características como legislação e taxas governamentais, relações políticas, pressões sociais e ambientais, as diferenças culturais, os costumes peculiares, limitações religiosas, o gosto do consumidor e mesmo as diferenças de línguas.

Com o intuito de clarear e definir alguns parâmetros estratégicos e táticos para o desenvolvimento de marcas de expressão global, o autor supracitado define sete premissas a serem consideradas:

1. Criação de um nome e símbolo cativante - Trata da necessária atenção a originalidade, facilidade de pronúncia em diversas línguas, ausência de associações conotativas negativas.

2. A dificuldade da associação do país - Aborda a importância de incorporar as diferenças culturais do mundo em sua marca.

3. Levando em consideração gostos e diferenças culturais - Considera problemas de aceitação da marca conforme os costumes locais. A marca deve apresentar a empresa e seus ideais, porém é importante aderir à sensibilidade local. 
4. Acondicionamento físico - Afirma a importância do entorno do produto, sua embalagem como aplicação do conceito da marca e apresenta esse suporte como uma possibilidade de base para disseminação global da marca.

5. Efeitos de pressões ambientais e sociais - Aborda a pressão mundial sobre os quesitos social e ambiental e estipula o desafio de uma marca em abarcar valores diferentes existentes em localidades sobre um mesmo assunto. Demonstra que o consumidor tende atualmente a considerar a entidade presente na marca, em sua responsabilidade e valores, comprometimento com temas sociais e ecológicos.

6. Diferente legislação de embalagem de consumo de país para país - Comenta a diversidade de legislações sobre embalagem e comunicação impressa em diferentes localidades. É comentada a dificuldade de padronização global e valorizado certo grau de uniformidade, surgido pelo comércio na União Européia ou mesmo pelo Acordo de Livre Comércio Norte Americano.

7. Economias da escala - Conceitua a importância de uma marca global manter-se organizada em sua expressão de unidade, não perdendo o controle de seu centro estratégico, controlando possíveis facções locais ou regionais.

Essas premissas mostram a complexidade do projeto de marcas de cunho global e a importante tarefa do designer em seus estudos para sua criação. O estudo apresentado é apenas uma parte das estratégias existentes para projeto de marcas de abrangência mundial.

Atualmente esta realidade multinacional tem estimulado estudos sobre a criação e gestão dessas marcas globais. Roellig (2007, pg.2) conclui que ainda existe muito a ser explorado sobre estratégias para uma marca de cunho global, cita que ainda são discutidas vantagens e desvantagens entre uma marca mundial e adaptações locais, entre associação com países definidos e incorporação de diferentes culturas.

\section{Considerações Finais}

Ao discursar sobre a criação e gestão de marcas, sobre o branding em um mundo globalizado, nota-se a complexa trama de conhecimentos necessários para tanto, advindos de áreas como marketing, administração, design, entre outras. Entende-se que o designer é uma peça fundamental importante para a criação e transmissão de significado e valor de uma marca, que por sua formação multidisciplinar aborda a emoção e personalidade necessária para a comoção dos consumidores perante a marca.

A marca global, em sua criação, é conceituada como mais complexa e exigente de mais recursos de pesquisa e gestão. Foram apresentados estudos de aspectos primordiais para assegurar a criação de uma marca e seu posicionamento global sem contratempos quanto a transmissão de sua mensagem por diversas nacionalidades.

Por fim, entende-se a complicada tarefa de projetar marcas de abrangência global, porém determina-se que o importante para a marca e sua expressão ampla é comunicar-se diretamente com seus clientes e se fazer presente na vida dos mesmos - em grandes ou pequenas proporções, porém marcantes. 


\section{Referências}

AAKER, David A. Marcas: Brand Equity gerenciando o valor da marca. São Paulo: Negócio Editora, 1998.

BEDBURY, Scott. O novo mundo das marcas: 8 princípios para a sua marca conquistar a liderança. Rio de Janeiro: Campus, 2002.

KOTLER, Philip; ARMSTRONG, Gary. Principios de Marketing. 7. ed Rio de janeiro: Prentice Hall do Brasil, 1998.

MUNARI, Bruno. Das coisas nascem coisas. São Paulo: Martins Fontes, 1998.

MARTINS, José Roberto. Branding: um manual para você criar, gerencial e avaliar marcas. São Paulo: Negócio, 2000.

NIEMEYER, Carla. Marketing no design gráfico. Rio de Janeiro: 2AB, 1998.

PINHO, J. B. O Poder das marcas. São Paulo: Summus, 1996.

ROELLIG, Lerry. DMI - Design Management Journal. Designing Global Brands: Critical Lessons. Disponível em: <http://www.dmi.org/dmi/html/publications/journal/pdf/01124ROE40.pdf>. Acesso em: 10 ago. 2007.

VILLAS-BOAS, André. O que é [e o que nunca foi] design gráfico. $2^{\mathrm{a}}$ ed. Rio de Janeiro: $2 \mathrm{AB}$, 1998. 